\title{
Influence of Supervision as a Motivation Factor on Stress Levels of Teachers in Public Primary Schools in Kajiado Central Sub-County, Kenya
}

\author{
Sadya Isabel Omondi, Njonge Teresia \\ 1. Masters Student in Education Guidance and Counselling of Egerton University \\ 2. Department of Psychology, Counseling and Educational Foundations, Egerton University
}

\begin{abstract}
Educationists and other stakeholders have recognized teachers' psychological wellbeing as a key aspect in teacher motivation. It has been used to judge the ability of teachers and thus the main determinant of teachers' performance and employment. Motivation hence has played an important role in the management of schools, because it may have a positive relationship with the stress levels of the teachers. The purpose of this study was to determine the influence of the teachers' supervision as a motivation factor on stress levels among public primary school teachers in Kajiado Central Sub-County. The study adopted a descriptive survey research design. The target population comprised of 826 public primary school teachers, and 80 deputy head teachers and 80 head teachers from the 96 public primary schools from Kajiado Central Sub-County. However, 16 of the public primary schools were located in areas with intercommunity clashes and poor road transport and therefore the entire target population was not practically accessible. The accessible population comprised of 697 public primary school teachers, 80 deputy head teachers and 80 head teachers from the 80 public primary schools. Sampling of the public primary schools and teachers was done using stratified random sampling while the sampling for head teachers and the deputy head teachers was done using purposive sampling. The total study sample size was 256 respondents, which comprises of 248 teachers and eight head teachers from eight public primary schools. Data was collected through questionnaires for teachers and interviews scheduled for head teachers. Data was analysed using Statistical Package for Social Sciences (SPSS) version 24. The study found that teachers' supervision significantly influenced the teachers stress levels in Kajiado Central Sub County. The findings may inform the Teachers Service Commission and the government policy makers on what needs to be changed or enhanced to promote motivational factors and reduce job stress among the primary school teachers.
\end{abstract}

Keywords: Influence of Supervision, Motivation, Stress levels, Kenya

DOI: $10.7176 / \mathrm{JEP} / 11-29-11$

Publication date:October $31^{\text {st }} 2020$

\section{Introduction}

Universal education has led to an increase in the growth of educational institutions all over the world. In Kenya, education is at the heart of the Social Pillar of Kenya Vision 2030 for sustainable development goal. The goal ensures inclusive and equitable quality education and promotes lifelong learning opportunities for all. This particular development goal is also essential for the success of all the other sustainable development goals (UNSECO, 2015). From a global perspective, educating a nation remains the most vital strategy for the development of the society throughout the developing world (Aikman \& Unterhalter, 2005). In essence, teachers are looked upon as the key stakeholders in the teaching profession. Therefore, their wellbeing is crucial in determining their output in the profession. Teachers like other workers in different professions do experience stress. Teacher stress refers to when the pressures upon a teacher exceed the resources to cope with those pressures. Stress in teaching profession restrains the quality of the teacher and creates a misery in the minds of the teachers. It erodes the peacefulness in the mind and life of teachers, it also has a negative effect on their work performance as well (Afful-Broni, 2012).

Teacher motivation plays an important role in the promotion of teaching and reduction of job stress levels among teachers. Motivational factors such as teachers' supervision may influence stress levels of a teacher (Areekkuzhiyil, 2014). Generally, motivated teachers are more likely to motivate pupils to learn much better in the classroom, it also promotes their satisfaction and fulfilment. While teacher motivation is fundamental to the teaching and learning process, several teachers are not highly motivated (Alam, 2011). This observation should be taken seriously and an investigation into the motivational factors influencing teacher stress levels is therefore necessary to achieve the educational goals in every learning institution.

According to a study by Sprenger (2011), $72 \%$ of the teachers in his sample describes the teaching profession as very stressful. The stress level of teachers is influenced by different motivational factors such as supervision, changes in remuneration as well as teacher-pupil interaction and workload. Other studies showed that gender and marital status contributed to the stress levels of teachers. Anbu (2015) found out that the stress level of male teachers was less affected by supervision, changes in remuneration, teacher-pupil interaction and workload 
compared to the female teacher. Married teachers were found to have more stress than unmarried teachers this was specifically due to workload from both the school and family. Areekkuzhiyil (2014) identified nine factors responsible for causing stress among teachers. These factors were interpersonal relationships in the school, professional and competence development, recognition in the school, work environment, autonomy in work, work family interaction, role conflict, job security and remuneration, and non-academic works. Studies reviewed on stressors in teaching by Okeke and Dalamin (2013), and Sulaiman and Akinsanya (2014) have also found poor pay and job security to contribute to stress among teachers.

In Kenyan context, Mwenda (2013) found that rural public primary school teachers have relatively high stress levels compared to urban school teachers. Their stress was influenced by supervision, changes in remuneration, teacher-pupil interaction and workload. Similarly, Wangai, (2012) found out that changes in remuneration was ranked as the most important factor towards job stress level. Other researchers like Karihe, Namusonge and Iravo (2015) found that stress levels among teachers led to unwanted behaviours like absenteeism, mistakes during work, drugs use and abuse and violence at work. The result effect of stress include complaints from parents and other stakeholders on the status of service delivery in the schools, frequent strikes and poor performance of the pupils in general, and eventually the overall image of the school gets damaged.

Despite the existence of vast literature on factors contributing to teachers stress in the county, a literature gap exists on the relationship between teachers' stress levels and teacher supervision. Previous studies conducted on the influence of motivational factors on the stress levels of teachers failed to capture the motivational factors such as supervision which is the focus of this study. Since education is under the Social Pillar of Kenya Vision 2030 and educationists and other stakeholders have recognized teachers' psychological wellbeing as a key determinant in teacher motivation, the study therefore contributes to the realization of these goals.

In Kajiado Central Sub-county, several schools have reported high stress level of teachers that is evidenced through resigning of teachers, cases of suicide and low teachers' motivation in teaching . Most teachers work under stress, in overcrowded classrooms and dilapidated buildings without the necessary learning resources (TSC Kajiado County Office, 2017) Poor enumeration and methods of teacher promotion may have contributed to the high stress levels of public primary school teachers in Kajiado Central which may be as a result of feedback from teachers' supervision. Among many other occupational stressors that affect teachers in Kajiado central is the introduction of FPE in Kenya in 2003 which added burden to teachers that caused more workload thus increasing stressful experiences among the teachers. Common symptoms of stress that has been observed among public primary school teachers in Kajiado central include irritability, mood swings and exhaustion, which later on escalated into depression, anxiety and lower quality of life of teachers (TSC Kajiado Central Office, 2017). Therefore, there is need to establish the influence of teachers' supervision as a motivational factor on stress levels of teachers in public primary school in Kajiado Central Sub-County, Kenya.

\subsection{Statement of the Problem}

Educationists and other stakeholders have recognized teachers' psychological wellbeing as a key aspect in teacher motivation. It has been used to judge the ability of teachers and thus the main determinant of teachers' performance and employment. Consequently, it has drawn the attention of researchers and education stakeholders in Kenya and elsewhere. In fact, many education researchers have been concerned with the question of motivational factors on stress levels of teachers across various schools and regions. In Kajiado County, more than $10 \%$ of teachers have quit the teaching profession due to the amount of stress at work. Others exhibit unwanted behaviour such as absenteeism, work related accidents, impaired decision-making, mistakes during work, drugs use and abuse and violence at work (TSC Kajiado County Office, 2017). Some schools in Kajiado County have applied several strategies of reducing teacher stress levels such as reducing the number of pupils per class, reducing the number of lessons per teacher, providing a conducive learning environment among others. Despite the possible strategies put in place by the school administrators to reduce the stress levels of teachers, teachers' stress levels are escalating day by day especially in Kajiado Central Sub-county which is in an urban set up that has the most schools in the entire Kajiado County, this concern has over the years posed the question of their psychological wellbeing. Despite the existence of vast literature on factors contributing to teachers stress in the county, a literature gap exists on the relationship between teachers' stress and teachers' supervision, yet there is coherence between the variables considered in the study. This study sought to bridge this existing gap by scrutinizing and shedding more light on the influence of teachers' supervision on stress levels among public primary school teachers in Kajiado Central Sub-County.

\subsection{Objectives of the Study}

To determine the influence of teachers' supervision as a motivation factor on stress levels of primary school teachers in Kajiado Central Sub-County, Kenya. 


\subsection{Research Hypotheses}

$\mathrm{H}_{01}$ There is no statistically significant influence of teachers' supervision as a motivation factor on stress levels of primary school teachers in Kajiado Central Sub-County, Kenya.

\section{Literature Review}

\subsection{Motivation and Teachers Stress Levels}

The education industry offer services in terms of moulding and crafting youngsters into good citizens of a country. This is where pupils learn good values and various techniques and strategies they can use as they grow up in life. These values, techniques and strategies are usually imparted to the pupils in all educational institutions through teaching methods that every teacher uses when conducting the lessons (Wigfield, Guthrie, Tonks \& Perencevich, 2004). Teaching is a very challenging job in which the teachers' performance is wrapped up in their personality. It requires a unique talent and sense of vocation if the teachers want to perform their role exceptionally well. According to Jali (2000) a very good teaching performance usually results when a teacher is motivated and teaches with enthusiasm, competence, effectiveness and with dedication to the profession. The teachers have to do dual tasks of instilling knowledge as well as ensuring that the pupils understand the concepts. Such concerns demand that those people teaching the pupils must be creative and practice diligently and faithfully. Like any other professional endeavours, those in the teaching career have a wide scope of social responsibilities to take care of.

The society has always expected a lot from the teachers such as to serve a large population as second parents dealing with the emotional tangles and torments of the adolescent stage of the youth entrusted to their care. Faced with this scenario, some teachers can tire of catering to individual needs and at the same time striving for professional excellence. Along this line Jarvis (2002) asserted that teachers often feel that they are under-motivated or burned out, this directly affects their teaching performance. Stress in the teaching profession restrains the quality of the teachers and at the same time creates a misery in the minds of the teachers due to heavy workload, low pay emoluments, lack of career development, and lack of communication, harassments in the school or college by peer teachers/workers/pupils/others and financial problems. Teachers stress erodes the peacefulness in the mind and life of teachers. It has a negative effect on their work performance.

Briner (2012) affirms on the one hand that stress is not always bad, in small doses, it can motivate one to perform better since stress is part of life's challenges. An acceptable level can serve as a challenge to improve the teachers' efficiency, though if the level of stress is such that the teacher will not be able to satisfactorily handle it, the result of teachers' efficiency may be negative. In the same vein, he claimed that stress is what keeps you alert and alive to tackle your responsibilities during presentation at work, it sharpens your concentration and even compels you to reach your target. However, if it is already beyond stipulated boundaries; stress may cause major damage to health, mood, relationships, efficiency and then productivity as well as the quality of one's life. Teacher stress may lead to strain (a reaction to stress) and teacher burnout (a state of emotional, physical and attitudinal exhaustion) which is usually accompanied by potentially pathogenic, physiological and biochemical changes resulting from aspects of the teacher's job. It is mediated by the perception that the demands made upon the teacher constitute a threat to his or her self-esteem or well-being and by coping mechanisms activated to reduce the perceived threat (Galton \& MacBeath, 2008).

A good teacher has not only to teach in a way that satisfies the class with the prominent teaching style, but must also manage time and other duties assigned to apart from teaching. These duties may include managing ethics and discipline in class, motivating pupils, ensuring pupils' interaction, and maintaining a proper link with the parents and the administration (Hanif, Hafeez \& Adnan Riaz, 2010). According to Bakker and Demerouti (2007) both job, resources and personal resources play a significant role in buffering the effects of job stress on the teachers' performance, in this case the resources act as a mean to achieve desired targets. The job resources mean those physical, psychological, social, or organizational facets of the job, which are functional in achieving work related goals, reduce job demands and the associated costs. These stimulate growth, learning and development. Personal resources refer to those resources, which are commonly associated with the people's self-evaluation, which enable them to control and influence their environment, this may also be referred to as motivational factors that enhance the teachers accomplish their work.

Motivation plays an important role when it comes to employee satisfaction and retention (Ramlall, 2004). The knowledge of what motivates people therefore is important to the manager (head teacher). The building of motivating factors into organizational roles and the entire process of leading people must be built on knowledge of motivation. Sobe (2013) asserts that the educational manager's job is not to manipulate people but rather to recognize what motivates people to perform best in their roles. The significance of teacher motivation is a crucial factor closely related to a number of variables in education such as pupil motivation, educational reform, teaching practice and teachers' psychological fulfilment and well-being (Kyriacou \& Kunc, 2007). Therefore, it is helpful for administrators to determine how to attract potential teachers and retain them in teaching.

Aswathappa (2005) asserts that teachers were better motivated if their work experience satisfies their needs. Motivation can direct behaviour (increased effort) that can be felt in improved performance. (Hoy and Miskel, 
2008). Aquinas (2006) argues that the primary task of managers is to motivate his/her subordinates so that they can come to work regularly and on time, to work hard and to make a positive contribution towards the achievement of organizational goals. Ousmame (2013) observed that embracing new technology and new ways of doing things determine institutions ability to renew itself and maintain a competitive edge over rivals. It was also noted that schools that were able to remain relevant in undertaking their key mandates to society focused on the human capital development through superior motivational rewards.

Sprenger (2011) reported that the teaching profession is stressful, with $72 \%$ describing the profession as extremely stressful. In studies conducted in China, it was found out that the stress level among teachers was very high and widely prevalent (Kyriacou and Chien, 2004; Meng and Liu, 2008). Those studies conducted in Australia, the United Kingdom and America cited the highest level of occupational stress compared to other professions. Causes of high level of teachers' stress were mentioned to be excessive workload and long working hours, poor pupil behaviour including aggression from the pupils and parents and pressures of assessment targets and inspection (Milbun, 2011). Nadeem, Rana, Lone, Maqbool, Naz and Ali (2011) observed that poor salary, excessive workload, poor infrastructure, lack of library facility, lack of teaching and learning material, teachers' morale, working relations with staff and head teacher and the working environment are the factors which affect the female teachers' performance negatively. Other factors include political interference, responsibilities at home, distance of residing area, stress, status of teacher and respect in society.

Studies carried out in Ghana, Lesotho, Namibia, Malawi, India, Pakistan and Zimbabwe showed that factors such as workload, teacher pupil ratio, living and working conditions, salary, recognition, and responsibilities contributed heavily to low or high levels of motivation in teaching (Voluntary Service Overseas, 2002). Ololube (2006) found that teacher related sources of job satisfaction such as good relationships with colleagues, better performance of learners among others and school related sources of job satisfaction such as participatory leadership, recognition, material rewards, advancement, pay and supervision had a greater impact on teachers' performance. Alderman (2008), and Dike (2009) found out that factors such as poor salaries, lack of resource and bad working conditions decreased teachers' morale and levels of commitments. It is clear that there are a lot of similarities in factors which increase motivation and reduce stress levels, the study's intention was to analyse the relationship between the teachers' supervision as a motivational factor and the teachers' stress level in relation to public primary schools in Central Kajiado County.

\subsection{Influence of Supervision on Stress Levels}

According to Alam (2011) if the head teacher is cooperative, democratic and friendly the teachers was motivated and become more responsible in their job. A study by Bod, Lankford, Loeb and Wyckoff (2003) showed that teachers who perceived their principal's supervision as participatory were significantly more satisfied with their job than those perceived the Principal's supervision as domineering. The study found that the older the principal the more satisfied were the teachers. The findings by Ololube (2006) showed that there was a significant relationship between democracy and teachers' job satisfaction. It indicated that democratic principles could improve the job performance among teachers. Other sources of stress have been linked to a lack of supervision, weak inspection systems, time constraints, a lack of regular performance feedback, inadequate management and participation management, and decentralized teachers monitoring systems working in large schools these systems inhibit effective supervision (Blix et al, 2014).

In the Kenyan context, the behaviour of school inspectors has been criticized due to unprofessional conduct which has had a serious impact on teaching and learning. Some of the criticism involves the inspectors harassing and being harsh to teachers in the midst of their pupils. They are found to be condescending and dictatorial, demanding for bribes, threatening and working against teachers just to prove their incompetence. Consequently, teachers have regarded inspection as very stressful due to the fear of the unknown (Wanzare, 2002). Therefore, according to Gardner (2010) it is important to design inspections in a way that focuses on classroom evaluation so as to offer support to teachers in determining the areas of weaknesses and improvement. This process should be done with care and consideration for school inspectors must realize that transformation among teachers cannot happen within a short period of time, and they should offer professional support rather than just criticism. The study also asserted that school inspection should consider an external monitoring and evaluation process that compliments the internal procedures such as self-evaluation and staff appraisal, as self-evaluation offers a set of comparative standardized perspective. Having a combined process may ensure positive results in that the feedback given may be more relevant, understandable, clear and useful. Furthermore, when the teachers are involved in the supervision process, the feedback given may have a high probability of being utilized in the recommendation process and when support is provided for them, both mechanisms promote school improvement and satisfy the demands for accountability. Aguti (2015) affirms that the teachers' supervision process was not meant to put more pressure upon schools and their systems but for accountability in the schools, appraise and evaluate the quality and standards of education of a school in an objective way. In the Kenyan context, school supervision is a basic component in monitoring teaching and learning process (Karanja, 2009). The success of any organization depends 
entirely on how effectively its workers are supervised. Therefore, every administration needs an inbuilt supervision system to provide the cohesion and direction necessary to achieve the purpose of the organization. Teachers are directly under the head teachers' supervision, who plays a vital role on the motivation of the teachers.

Muriithi (2011) concluded that most head teachers do not perform their instructional supervisory duties, for instance, classroom observation, checking pupils notes and teaching notes frequently. As a result, schools where the head teacher did minimal instructional supervisory duties experienced inadequate learning outcomes. Kiruja, and Mukuru (2013) found that among the challenges being faced by head teachers are heavy workload and poor relationships with the teachers they supervise who felt being policed and victimized and denied promotion. Okumbe (1998) adds that instructional practices involve such activities as helping in the formulation and implementation of schemes of work, evaluating and overseeing modification of instructional programs and delivering instructional resources. Other activities include conducting and coordinating staff in-service, advising and assisting teachers involved in instructional programs. These instructional activities are mainly carried out to support, motivate and stimulate the teachers to assist them improve their classroom instructions. When principals support the teachers in this way the pupils' academic achievement is improved. These processes of instructional activities help the teachers to identify teaching and learning problems and seek various alternative solutions. In Kenya, Ngari, et al (2013) established that the school administrators experienced stress in their work. The authors found that $54.5 \%$ of the respondents recorded high levels of stress resulting from their school workload and other responsibilities, of the reviewed studies. The previous studies have majorly focussed on school workload and stress, less studies have been done on the correlation between supervision and stress levels especially in Kajiado County. The current study is intending to fill this research gap.

\subsection{Theoretical Framework}

This study adopted two theories; one for motivational factors and one for stress. These theories are; Two Factor Theory advanced by Fredrick and the Lazarus Theory of Psychological Stress.

\subsubsection{Two Factor Theory}

This study adapted The Two Factor Theory advanced by Fredrick. In the 1950's psychologist Frederick Herzberg proposed a theory of motivation that focuses on the job and on the environment where work is done (Tyner, 2007). Herzberg studied various factors relating to the job and their relation to employee motivation and concluded that they can be divided into hygiene (extrinsic) factors and motivational (intrinsic) factors (Tyner, 2007; Mahmood \& Mahmood, 2010). Hygiene factors, relates to the work setting and not the content of the work, these may include things like adequate wages, comfortable and safe working conditions, fair company policies, and job security (Tyner, 2007). These factors do not necessarily motivate employees to excel but will definitely have an effect on the employee's performance, though their absence may be a potential source of employee dissatisfaction (Tyner, 2007).

Many people feel that a good salary is one of the most important job factors, even more important than job security (Tyner, 2007; Mahmood \& Mahmood, 2010). Salary and security make it possible for employees to satisfy the physiological and security needs identified by Abraham Maslow in his theory of needs. However, the presence of hygiene factors is unlikely to motivate employees to work harder. According to Herzberg, the hygiene factors cannot be regarded as motivators. The motivational factors yield positive satisfaction. These factors are inherent to work and motivate the employees for a superior performance and employees find these factors intrinsically rewarding. The motivators symbolized the psychological needs that were perceived as an additional benefit.

Motivational factors, which relate to the content of the work itself, include achievement, recognition, involvement, responsibility, and advancement (Tyner, 2007). The absence of motivational factors may not result in dissatisfaction, but their presence is likely to motivate employees to excel. The practical implications of Herzberg's theory apply to all employees, including teaching staff of primary schools.

In Kenya, motivation takes the dimensions of hygiene factors and motivational factors (Ngari et al, 2013). Literature on the subject in a Kenyan context indicates that teaching staff of primary schools is mainly motivated by the hygiene factors, particularly, salaries and allowances (Karanja, 2009). However, the effect of the motivational factors on employee performance is also much appreciable (Muriithi, 2011). Generally, Herzberg's theory supports the effect of motivation on employees' performance regardless of the sector involved. Yet, the effect of motivation (i.e. the hygiene and motivational factors) is based on the dimensions of motivation used in the primary school. According to Okumbe (1992), Herzberg's Theory of motivation may enhance teachers' motivation when the head teacher provides clear and regular feedback to the teachers and also improve on their environment so that the teachers may work in an enabling environment and hence reduce their level of stress.

\subsubsection{The Lazarus Theory of Psychological Stress}

In his monograph on emotion and adaptation, developed a comprehensive emotion theory that also includes a stress theory (Lazarus,1993). This theory distinguishes two basic forms of appraisal, primary and secondary appraisal (Lazarus, 1966). These forms rely on different sources of information. Primary appraisal concerns whether something of relevance to the individual's well-being occurs, whereas secondary appraisal concerns 
coping options. Within primary appraisal, three components are distinguished: goal relevance described as the extent to which an encounter refers to issues about which the person cares, goal congruence defines the extent to which an episode proceeds in accordance with personal goals and that of ego- involvement that designates aspects of personal commitment such as self-esteem, personal values, ego-ideal, or ego-identity. Likewise, three secondary appraisal components are distinguished: blame or credit results from an individual's appraisal of who is responsible for a certain event. By potential Lazarus means a person's evaluation of the prospects for generating certain behavioural or cognitive operations that will positively influence a personally relevant encounter and future expectations refer to the appraisal of the further course of an encounter with respect to goal congruence or incongruence.

Specific patterns of primary and secondary appraisal lead to different kinds of stress. This definition of stress encompasses a number of themes that capture the transactional nature of stress and those processes that best express the nature of that transaction. These themes involve the following: Stress is a product of the transaction between the individual and the environment. The authority and power of the transaction lies in the process of appraisal that binds the person and the environment and it is this "relational meaning" (Lazarus \& Folkman, 2001) that the person constructs from the transaction and that lies at the heart of the stress process. Three types are distinguished: harm, threat, and challenge (Lazarus \& Folkman, 1984). Harm refers to the (psychological) damage or loss that has already happened, threat is the anticipation of harm that may be imminent, challenge results from demands that a person feels confident about mastering. These different kinds of psychological stress are embedded in specific types of emotional reactions, thus illustrating the close conjunction of the fields of stress and emotions. When motivational factors are altered in school set ups, primary appraisal occurs whereby teachers' stress levels are affected. How teachers cope with the change of motivational factors is described in secondary appraisal of this theory. When the adaptation to changes in motivational factors is hard, slow or impossible, stress levels increase and vice versa.

\subsection{Conceptual Framework}

According to Kombo and Tromp (2006), a concept is an abstract or general idea inferred or derived from specific instances. A conceptual framework is a set of broad ideas and principles taken from relevant fields of enquiry used to structure a subsequent presentation. Kothari (2004) defines an independent variable also known as the explanatory variable as the presumed cause of the changes of the dependent variable. Dependent variable refers to the variable which the researcher wishes to explain. In this conceptual framework, teachers' stress level is dependent on the independent variable of the study which are the influence of teachers' supervision. These independent variable may be controlled, manipulated or moderated by government policy, management policy and personality trait which serve as the intervening variables in this study. Therefore, government policy, management policy and personality traits of teachers were the intervening variables of the study. The conceptual framework for the study is as shown in figure below

\section{Independent Variables}

Dependent Variable

Intervening Variables

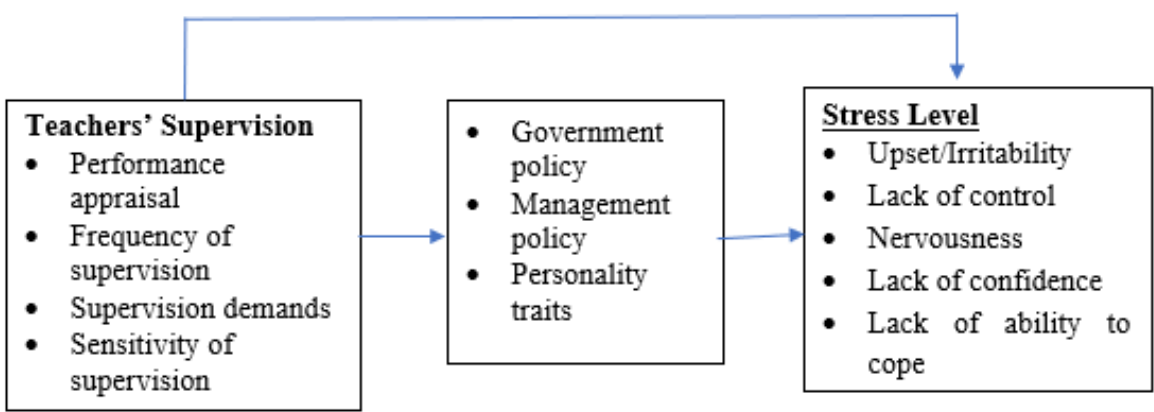

Figure 1: Influence of Supervision as a Motivational Factor on Stress Levels of Teachers

\section{Research Methodology}

\subsection{Research Design}

The study adopted a descriptive survey research design to obtain information.

\subsection{Target Population}

The study targeted 826 public primary school teachers, 80 head teachers and 80 deputy head teachers from the 96 public primary schools in Kajiado Central Sub-County. However, 16 of the public primary schools are located in areas with intercommunity clashes and poor road transport and therefore the entire target population was not 
practically accessible. The accessible population of the study therefore comprised of 697 public primary school teachers, and 80 head teachers and 80 deputy head teachers from the 80 public primary schools from Kajiado Central Sub-County.

\subsection{Sampling Procedure and Sampling Size}

In line with Mugenda and Mugenda (2003), a sample size equivalent to $10 \%$ of the population is considered adequate for a descriptive study, this study therefore used a sample size of eight primary schools which was selected using stratified random sampling. The stratified random sampling technique was used since it allows the researcher to take into account the population's different subgroups and guaranteed that the sample accurately represented the population on specific characteristics (Jackson, 2014). The five wards in Kajiado Central Subcounty formed the stratification criteria. To do this, the list of all primary schools in Kajiado Central Sub-county was obtained from the TSC office in Kajiado County and eight primary schools cross all the five wards in Kajiado Central Sub-county. Therefore, using stratified random sampling, two schools were selected from Ilbissi ward, two schools from Kajiado ward, two schools in Eukarika ward, one school in Namanga ward, and one schools in Elangata ward.

Krejcie and Morgan (1970) formula was used to determine the sample size of teachers as follows;

$$
\mathrm{S}=\frac{\mathrm{X}^{2} \mathrm{NP}(1-\mathrm{P})}{\mathrm{d}^{2}(\mathrm{~N}-1)+\mathrm{X}^{2} \mathrm{P}(1-\mathrm{P})}
$$

Where:

$\mathrm{S}=$ Required Sample size

$\mathrm{X}=\mathrm{Z}$ value (e.g. 1.96 for $95 \%$ confidence level)

$\mathrm{N}=$ Population Size

$\mathrm{P}=$ Population proportion (expressed as decimal and assumed to be $0.5(50 \%)$ )

$\mathrm{d}=$ Degree of accuracy (5\%), expressed as a proportion (0.05); It is margin of error

$\mathrm{S}=248$ teachers

The 248 teachers were selected using stratified random sampling with the five wards as the stratification criteria. This implies that the number of teachers from each ward was proportionate to the number of teachers in the ward. The following expression was used;

Sample $=\frac{248 \text { (Sample size of teachers })}{697 \text { (Population of teachers })} \times$ Total Number of Teachers in the Ward

Using the formula, 80 teachers were selected from Ilbissi ward, 56 teachers from Kajiado ward, 46 teachers from Eukarika ward, 38 teachers from Namanga ward, and 28 teachers from Elangata ward. Additionally, one head teacher was purposively sampled from each of the sampled 8 primary schools to make a total of 256 respondents for the study.

\subsection{Validity of the Research Instrument}

This study obtained its data through the administration of questionnaires to teachers based on the research objective. The rating scales on supervision comprised of descriptions such as strongly agree, agree, undecided, disagree and strongly disagree. In this study, respondents filled the questionnaire based on a five-point Likert scale. The rating was scored as follows; $5=$ Strongly Agree, $4=$ Agree, $3=$ Neutral, $2=$ Disagree, $1=$ Strongly Disagree.

The students' self-esteem was measured using stress inventory on Perceived Stress Scale (PSS) by Sheldon (1994) which is a standardized research inventory that was adopted. The Perceived Stress Scale (PSS) was selected because it is, arguably, the most widely-used stress measure in social science research. The teachers completed the stress scale as part of a questionnaire comprising a range of personality and social measures. Scoring of the selfesteem test was as follows, $0=$ Never, $1=$ Rarely, $2=$ Sometimes, $3=$ Often and $4=$ Always. Items with an asterisk (stated on negative) was reverse scored, that is, $4=$ Never, $3=$ Rarely, $2=$ Sometimes, $1=$ Often and $0=$ Always. The higher the score, the higher the stress level (Crandal, 2013).

The researcher opted to interview the head teachers because interviews presents oral-verbal information. Interviews provide in-depth information from the respondents. It is also friendly, flexible and easily adaptable to the interviewee. This study required detailed information from the head teachers in regard to teacher supervision, changes in teacher remuneration, teacher-pupil interaction, workload that teachers face as well as stress involved in teaching which would not be obtained using questionnaires and therefore the choose of interview guides were to complement data obtained through research questionnaires.

\subsubsection{Validity of Instruments}

To ensure content validity of the research instruments, the researcher constructed the questionnaire and the interview schedule in line with the research objective of the study. Additionally, to ensure face and content validity, the researcher also consulted research supervisor of this study and lecturers from the Department of Psychology, Counselling, and Educational Foundations to provide feedback on the validity of the instruments. 


\subsubsection{Reliability of Research Instruments}

A test- Retest approach was used to gauge the reliability of the research questionnaires based on a pilot study. The correlation coefficient of the results from the two tests was calculated using Spearman rank correlation. A coefficient of 0.762 was found which implied that the research questionnaires were reliable for use in this study.

\subsection{Data Analysis}

The filled research questionnaires was coded and entered into statistical package for social science (spss) version for quantitative data analysis. Both descriptive and inferential statistics were used in analysing the data. For descriptive statistics, frequencies, mean, and standard deviation were derived. For inferential statistics, simple linear regressions were done to test the hypotheses of the study. In order to control Type I and Type II errors, the researcher selected a low significance level of 0.05 . Qualitative data from the interviews were reported in verbatim, transcribed and coded according to various themes, categories and sub categories as per objectives as they emerge during the study using NVivo version 12 software. The results of the analysis were presented by the use of tables and narrative form.

\section{Results and Discussions \\ 4.1 Descriptive Findings \\ 4.1.1 Teachers' Supervision}

The study used the following indicators, sensitivity to the emotional wellbeing and self-care needs, enhancement of skills to deal with socio-cultural issues in an interpersonally sensitive manner, experience for a richer and more accurate appraisal, provision of a safe place for emotional ventilation and support, patterns of emotional response, freedom to work independently, demands to meet, fear towards seniors and concerns with the performance at the expense of psychological wellbeing. Table 1 shows the descriptive findings.

Table 1

Influence of Teachers' Supervision on Stress Levels

\begin{tabular}{|c|c|c|c|c|c|c|c|}
\hline \multirow[t]{2}{*}{ Description } & \multicolumn{5}{|c|}{ Frequency and Percentages } & \multicolumn{2}{|c|}{ Total } \\
\hline & SD & D & $\mathbf{N}$ & $\mathbf{A}$ & SA & Mean & $\begin{array}{l}\text { Std. } \\
\text { Dev }\end{array}$ \\
\hline $\begin{array}{l}\text { The supervision is sensitive to my emotional wellbeing } \\
\text { and self-care needs. }\end{array}$ & $\begin{array}{c}6 \\
(2.7 \%)\end{array}$ & $\begin{array}{c}18 \\
(8.1 \%)\end{array}$ & $\begin{array}{l}16 \\
7.2 \%)\end{array}$ & $\begin{array}{c}158 \\
(71.5 \%)\end{array}$ & $\begin{array}{c}23 \\
(10.4 \%)\end{array}$ & 3.79 & 0.839 \\
\hline $\begin{array}{l}\text { Supervision enhanced my skills to deal with socio- } \\
\text { cultural issues in an interpersonally sensitive manner. }\end{array}$ & $\begin{array}{c}7 \\
(3.2 \%)\end{array}$ & $\begin{array}{c}13 \\
(5.9 \%)\end{array}$ & $\begin{array}{c}5 \\
(2.3 \%)(\end{array}$ & $\begin{array}{c}174 \\
(78.7 \%)\end{array}$ & $\begin{array}{c}22 \\
(10.0 \%)\end{array}$ & 3.86 & 0.792 \\
\hline $\begin{array}{l}\text { The supervision experience has given me a richer and } \\
\text { more accurate appraisal of myself with a view of } \\
\text { reducing stress. }\end{array}$ & $\begin{array}{c}8 \\
(3.6 \%)\end{array}$ & 22 & 9 & $\begin{array}{l}155 \\
70.1 \%)(\end{array}$ & $\begin{array}{c}27 \\
12.2 \%)\end{array}$ & 3.77 & 0.916 \\
\hline $\begin{array}{l}\text { Supervision provided a safe place for emotional } \\
\text { ventilation and support. }\end{array}$ & $\begin{array}{c}5 \\
(2.3 \%)\end{array}$ & $\begin{array}{c}27 \\
(12.2 \%)\end{array}$ & $\begin{array}{c}13 \\
(5.9 \%)\end{array}$ & $\begin{array}{c}143 \\
(64.7 \%)(\end{array}$ & $\begin{array}{c}33 \\
(14.9 \%)\end{array}$ & 3.78 & 0.925 \\
\hline $\begin{array}{l}\text { The supervision helped me understand my patterns of } \\
\text { emotional responding. }\end{array}$ & $\begin{array}{c}12 \\
(5.4 \%)\end{array}$ & $\begin{array}{c}18 \\
(8.1 \%)\end{array}$ & $\begin{array}{c}14 \\
(6.3 \%)\end{array}$ & $\begin{array}{c}148 \\
(67.0 \%)(\end{array}$ & $\begin{array}{c}29 \\
(13.1 \%)\end{array}$ & 3.74 & 0.973 \\
\hline $\begin{array}{l}\text { Supervision does not give me freedom to work } \\
\text { independently. }\end{array}$ & $\begin{array}{c}30 \\
(13.6 \%)\end{array}$ & $\begin{array}{l}151 \\
(68.3 \%)\end{array}$ & $\begin{array}{c}12 \\
(5.4 \%\end{array}$ & $\begin{array}{c}22 \\
(10.0 \%)\end{array}$ & $\begin{array}{c}6 \\
(2.7 \%)\end{array}$ & 2.20 & 0.892 \\
\hline Supervision demands are high to meet. & $\begin{array}{c}29 \\
(13.1 \%)\end{array}$ & $\begin{array}{c}154 \\
(69.7 \%\end{array}$ & 11 & $\begin{array}{c}20 \\
9.0 \%)\end{array}$ & $\begin{array}{c}7 \\
(3.2 \%)\end{array}$ & 2.19 & 0.891 \\
\hline Supervision creates fear towards 1 & $\begin{array}{c}24 \\
(10.9 \%)\end{array}$ & $\begin{array}{c}153 \\
(69.2 \%)\end{array}$ & $\begin{array}{c}6 \\
2.70\end{array}$ & $\begin{array}{c}28 \\
12.7 \%)\end{array}$ & $\begin{array}{c}10 \\
(4.5 \%)\end{array}$ & 2.31 & 0.980 \\
\hline $\begin{array}{l}\text { Supervisors are only concerned with my } \\
\text { and not my psychological wellbeing. }\end{array}$ & $\begin{array}{c}23 \\
(10.4 \% \\
\end{array}$ & $\begin{array}{r}146 \\
(66.1 \% \\
\end{array}$ & $\begin{array}{l}8 \\
.6 \% \\
\end{array}$ & $\begin{array}{r}36 \\
16.3 \% \\
\end{array}$ & $\begin{array}{c}8 \\
3.6 \%) \\
\end{array}$ & 2.37 & 0.994 \\
\hline
\end{tabular}

Note: $\mathrm{SA}=$ Strongly Agree, $\mathrm{A}=$ Agree, $\mathrm{N}=$ Neutral, $\mathrm{D}=$ Disagree, $\mathrm{SD}=$ Strongly Disagree

The study obtained a mean score of 3.79 and a standard deviation of 0.839 in regard to the sensitivity of the supervision to the emotional wellbeing and self-care needs. The mean score obtained was in the range 3.5 and 4.5 and therefore it implied that on average the teachers tended to agree that supervision was sensitive to the emotional well-being and self-care needs. This is due to $71.5 \%$ of the teachers representing the majority indicating that they agreed with the statement. This could be due to good working relationship between teachers and their supervisors and thus being sensitive in the supervisory duties. A standard deviation of less than 1.0 implied that the teachers were in consensus in rating the statement. This further implied that a majority of the teachers gave responses close to the mean. This concurred with a study by Sariah, Hassan, and Ibrahim (2018) who posited that if the head teacher is cooperative, democratic and friendly the teachers was motivated and become more responsible in their job.

A mean of 3.86 and a standard deviation of 0.792 were achieved in respect to enhancement of skills by 
supervision to deal with socio-cultural issues in an interpersonally sensitive manner. The mean score obtained was in the range of 3.5 and 4.5 which implied that on average the teachers tended to agree that there was an enhanced skill of supervision to deal with socio cultural issues in an interpersonally sensitive manner. This was due to the fact that majority of the teachers $(78.7 \%)$ indicated that they agreed with the statement. This could be possible through enabling teachers adopt best instructional practices in their teaching. A standard deviation of less than 1.0 implied that the respondent were in consensus in rating the statement. Majority of the teachers giving responses close to means further evidences this. This is in agreement with a research by Yong (2018) that supervision should include conducting and coordinating staff in-service, advising and assisting teachers involved in instructional programs.

In respect to the richness and more accurate appraisal of the self with a view of reducing stress due to supervision, the study obtained a mean of 3.77 and a standard deviation of 0.916 . The mean score obtained is in the range of 3.5 and 4.5 and therefore it implied that on average teachers tended to agree that supervision enhanced a more accurate of the self. This was because majority of the teachers (70.1\%) indicated that they agreed with the statement. This implied that there was an objective appraisal for teachers in Kajiado Central Sub County. Majority of the teachers giving responses close to mean further evidences this (standard deviation of 0.916). This was in line with Johnston (2018) who said that it was important to design inspections in a way that focuses on classroom evaluation so as to offer support to teachers in determining the areas of weaknesses and improvement.

With respect to the provision of a safe place for emotional ventilation and support, the study was able to establish that supervision obtained a mean of 3.78 and a standard deviation of 0.925 . The mean score was in the range of 3.5 and 4.5 and therefore it implies that on average the respondent tended to agree that supervision provides a safe place for emotional ventilation and support. This was because majority of the teachers $(64.7 \%)$ indicated that they agreed with the statement. This implied that in Kajiado Central, teachers were able to express themselves and were assisted in their weaknesses through the teacher supervision. The teachers giving responses close to the mean evidence this. Emmanuel (2015) asserts that teachers need space to express their emotions in the midst of supervision in order to reduce teacher stress.

On the issue of being helped to understand the patterns of emotional responding, the study established a mean of 3.74 and a standard deviation of 0.973 with regard to supervision. The mean score obtained was in the range of 3.5 and 4.5 and therefore it implies that on average teachers tended to agree that supervision helped with the understanding of the emotional patterns this was because the majority of the teachers $(67.0 \%)$ indicated that they agreed with the statement. A standard deviation less than 1.0 implied that the teachers giving responses close to mean. Supervisory guidelines for teacher provides that teachers needs to be understood by responding to different emotional patterns displayed by teachers and being ethically sound in the entire process (Mwai \& Muchanje, 2018).

The study obtained a mean of 2.20 and a standard deviation of 0.892 the freedom to work independently due to supervision. The mean score was in the range of 1.5 and 2.5 and therefore implies that on average the teachers agreed that supervision enabled the freedom to work independently. This was because of the majority of teachers $(68.3 \%)$ indicated that they disagreed with the statement that supervision does not give me freedom to work independently. A standard deviation of less than 1.0 implied that teachers were in consensus in rating the statement. This was further evidenced by majority of the teachers giving responses close to the mean. This in line to the head teachers' interview, one of them indicated that;

"most teachers value supervision but they also need to have some freedom hence our presence as supervisors is appreciated but at a controlled level".

The findings further differed with the findings by Balakrishnan, Bahari, and Paul (2017) showed that there was a significant relationship between freedom and teachers' job satisfaction. The study by Balakrishnan, Bahari, and Paul (2017)was done among pre-service teachers and thus were not exposed to much supervision and thus the reason why the study findings differed with the current study that was done among experienced teachers.

A mean score of 2.19 and a standard deviation of 0.891 were achieved in respect to meeting high demands as a result of supervision. The mean score obtained was in the range of 1.5 and 2.5 and therefore this implied that on average teachers tended to disagree that supervision led to meeting high demands. This was because majority of the teachers $(69.7 \%)$ indicated that they disagreed with the statement. This implied that in Kajiado Central, most of primary school teachers met the demands of supervision and thus a low likelihood of stress. A standard deviation less than 1.0 implying that the teachers were in consensus with the rating as evidenced by majority of the teachers giving close responses to the mean. This was in line with Aguti (2015) who affirmed that the teachers' supervision process was likely to put more pressure upon schools and their systems.

In respect to creating fear towards the seniors, the study obtained a mean score of 2.31 and a standard deviation of 0.980 . The mean score obtained was in the range of 1.5 and 2.5 and therefore implies that on average teachers tended to disagree that supervision created fear towards seniors. This was because the majority of the teachers $(69.2 \%)$ indicated that they disagreed with the statement that supervision creates fear towards my seniors. This is an indication of possible unfriendly supervision of primary school teachers in Kajiado Central Sub-County. A standard deviation of less than 1.0 implied that teachers were in consensus in rating the statement as evidenced 
by the majority of the teachers giving close to mean. This is in line with the head teachers' interview who said; "the supervision exercise is mostly not filled with fear since most of the teachers are long time colleagues and they mostly take the activities in a friendly manner".

However, Nizam and Adil (2014) that teachers have regarded inspection as very stressful due to the fear of the unknown.

A mean score of 2.37 and a standard deviation of 0.994 were achieved in respect to the concern that the supervisors were only concerned with performance and not psychological wellbeing. The mean score obtained was in the range of 1.5 and 2.5 and therefore implies that on average teachers tended to disagree that supervisors were only concerned with the performance and not the psychological wellbeing. This was because majority of the teachers $(66.1 \%)$ indicated that they disagreed with the statement. A standard deviation of less than 1.0 implied that the teachers were in consensus in rating the statement. This is further evidenced by the majority of the teachers giving responses close to the mean. The findings are in line with a study by Borg, Kembro, Notander, Petersson, and Ohlsson (2017) which established that teacher related sources of job satisfaction such as good relationships with colleagues, better performance of learners greater impact on teachers' performance.

\subsubsection{Teachers' Levels of Stress}

The following indicators were used to examine the stress levels of teachers; frequency of being upset, because of something that had happened unexpectedly being unable to control the important things in your life, being nervous, being confident about your ability to handle your personal problems, feeling that things were going your way, finding that you could not cope with all the things that you had to do, controlling irritations in your life, being angered because of things that were outside of your control, feeling difficulties were piling up so high that you could not overcome them. Table 2 shows the descriptive findings of the study.

Table 2

Descriptive Statistics for Teachers' Levels of Stress

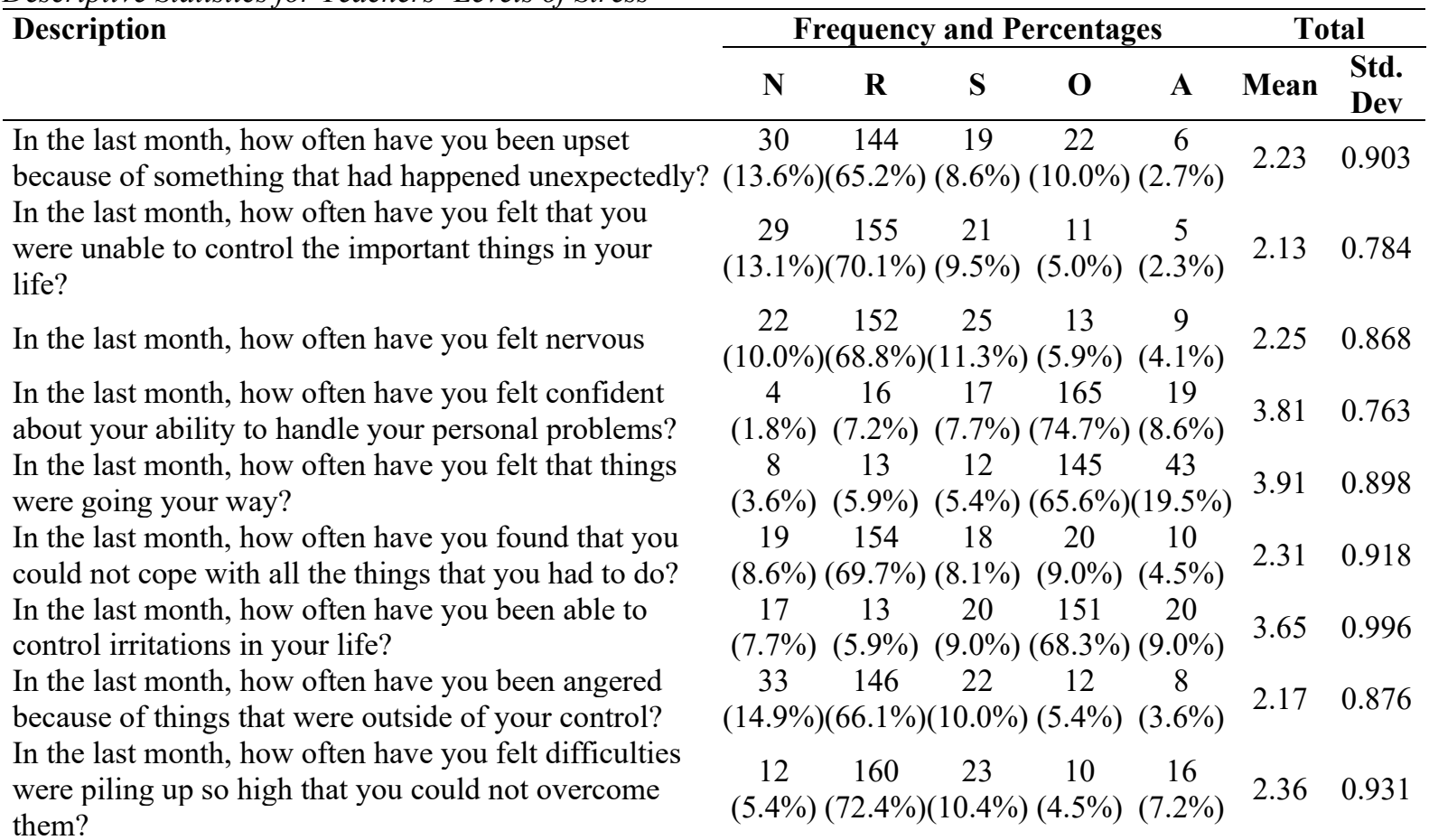

Note: $\mathrm{N}=$ Never, $\mathrm{R}=$ Rarely, $\mathrm{S}=$ Sometimes, $\mathrm{O}=$ =ften, $\mathrm{A}=$ Always

In regard to the frequency of being upset because of something that had happened unexpectedly, the study obtained a mean of 2.23 and standard deviation of 0.903 . The achieved mean score implied that on average the teachers rarely were upset because of something that had happened unexpectedly. This is further supported by $13.6 \%$ of teachers who indicated they never felt upset and $65.2 \%$ who felt that they rarely upset. The achieved standard deviation inferred that there was consensus among the teachers in rating the aspect of being upset. Majority of the interviewed head teachers said that teachers were quite often upset by certain happenings in and outside schools, which led to the affected teachers being outside the school. Saqib and Rehman (2018) that indicated that teachers were upset by various things in schools such as poor remuneration, administrative challenges, workload and student management.

The study further sought to examine how the teacher controlled certain things in their life. In respect to this, the study obtained a mean of 2.13 and a standard deviation of 0.784 . the achieved mean score implied that teachers were rarely felt that you were unable to control the important things in your life. This is further supported by $70.1 \%$ 
of the teachers who indicated that they rarely felt that they were unable to control the important things in their life. Similarly, the study found out that teacher felt nervous due to a mean of 2.25 and a standard deviation of 0.868 on the frequency of being nervous in the last month. Majority of the teachers $(65.2 \%)$ also indicated that they rarely felt nervous in their teaching profession. This findings significant differ with those by Pokhrel (2017) that indicated that teachers were unable to perform certain duties due to nervousness. Head teachers indicated that;

"Sometimes teachers are disturbed by their private issues and bring them on the teaching profession leading to teachers' ineffectiveness, yes teachers undergo various kings of stress and nervousness".

The study obtained a mean of 3.81 and a standard deviation of 0.763 in regard to feeling of confidence about the ability to handle personal problems. The mean score was in the range of 3.5 and 4.5 which implied that the teachers on average often felt confidence about the ability to handle their personal problems. This was also because majority of the teachers $(70.1 \%)$ indicated that they often felt confidence about the ability to handle their personal problems. A standard deviation less than 1.0 implied that teachers were in consensus in rating the statement as also evidenced by majority of the teachers giving responses close to mean. Baraza and Gogo (2016) found that majority of teachers were courageous and felt confident to solve their own problems. Head teachers indicated that;

"most teachers prefer to handle and manage stress and their own level and seek counselling from avenues away from the school. The y are confident that they can be able to overcome ether stress".

A mean of 3.91 and a standard deviation of 0.898 was achieved in regard to the feeling that things were going their own way in the last month. The mean score achieved implied that the teachers on average felt that things were going their own way in the last month. This was because majority of the teachers $(68.8 \%)$ indicated that they felt that things were going their own way in the last month. A standard deviation less than 1.0 implied that teachers were in consensus in rating this aspect and that majority of the teachers gave responses close to mean.

The study obtained a mean of 2.31 and a standard of 0.918 in regard to the frequency of being able to cope with all things to be done. The mean achieved was in the range of 1.5 and 2.5 which implied that on average the teachers rarely found that they could not cope with all the things that they had to do. This was because of majority of the teachers $(69.7 \%)$ indicating that they rarely found that they could not cope with all the things that they had to do. A standard deviation less than 1.0 implied that teachers were in consensus in rating this aspect. Yong (2018) also found that teachers attempt to solve their own problems and could cope with the pressures of work place, especially those with high working experience.

A mean of 3.65 and a standard deviation of 0.996 were achieved in regards to the frequency of the ability to control irritations in own side of life. The mean score obtained was an indication that the teachers on average were often able to control irritations in their life, an aspect that was further evidenced by majority of the teachers $(68.3 \%)$ who supported the metric. Wanjala, Osendo and Okoth (2019) asserts that ability of a teacher to control emotions and irritations is an indication of less tress to such a teacher. A standard deviation less than 1.0 implied that teachers were in consensus in rating the statement as further evidenced by majority of the teachers giving responses close to mean. This is in disagreement to the finding by Saqib and Rehman (2018) that most teachers were unable to control their frustrations and ended up translating to students. Head teachers also indicated that;

"In the past, some teachers have expressed their frustrations openly and even to the students which resulted to interdiction of the affected teachers. This was due to stress they were undergoing".

Similarly and in respect to the frequency of being angered due to things being out of control, the study obtained a mean of 2.17 and a standard deviation of 0.876 . The achieved mean score implied that the teachers on average were rarely angered because of things that were outside of their control. The achieved standard deviation implied that teachers were in consensus in rating this aspect of being angered by things that were outside of their control. This indicates that primary school teachers in Kajiado Central sub-county were less angered and thus an indication of less stress.

A mean score of 2.36 and a standard deviation of 0.931 were achieved with regard to the frequency of difficulties piling up so high to be overcome. The mean score achieved was in the range of 1.5 and 2.5 and this implied that on average the teachers rarely felt difficulties were piling up so high that they could not overcome them. This was because majority of the teachers (72.24\%) indicated that rarely does this aspect occurs. The standard deviation achieved implied that teachers in consensus in rating the statement and that majority of the teachers gave responses close to mean score. Head teacher said that;

"Sometimes the pressure on teachers is too much in addition to pressures of their own private life. Some teachers end of committing suicide but is never brought into the news or the cause of death is attributed to other cause such as blood pressure"

\subsection{Inferential Statistics}

The study used simple linear regression for the inferential statistics. The simple regressions were used to test the study hypotheses. The hypothese was tested at 5\% significance level to avoid Type I and Type II error.

4.2.1 Influence of Supervision on Stress Levels

The hypothesis stated that there is no statistically significant influence of supervision on stress levels of primary 
school teachers in Kajiado Central Sub-County, Kenya. This hypothesis was tested using simple linear regression. The first model regressed stress of teachers against teacher supervision. Table 3 shows the summary.

Table 3

Influence of Teacher Supervision on Stress Levels of Teachers

\begin{tabular}{ccccc}
\hline & $\mathrm{R}$ & R Square & Adjusted R Square & Std. Error of the Estimate \\
1 & 0.475 & 0.226 & 0.222 & 0.12891 \\
\hline
\end{tabular}

Predictors: (Constant), Supervision

According to Table 3, the study established that there was a moderate correlation between the observed values of stress and the predicted values of stress. This was due to R-value of 0.475 . This indicates that the model was moderately of good quality. R Square value of 0.226 achieved implied that supervision explained for $22.6 \%$ of the variation in the stress levels of teachers. The standard error of estimate was 0.12891 implying that there was low error in the model and hence high precision. To establish the significance of the model, ANOVA was carried out as shown in Table 4.

Table 4

Analysis of Variance for the Influence of Teacher Supervision on the Level of Teacher Stress

\begin{tabular}{llccccc}
\hline Model & & Sum of Squares & df & Mean Square & F & Sig. \\
\hline \multirow{2}{*}{1} & Regression & 1.062 & 1 & 1.062 & 63.922 & 0.000 \\
& Residual & 3.639 & 219 & 0.017 & & \\
\hline & Total & 4.701 & 220 & & & \\
\hline
\end{tabular}

Dependent Variable: Stress

Predictors: (Constant), Supervision

Table 4 indicates that the model was statistically significant due to $\mathrm{F}(1,219)=63.922$ and $\mathrm{P}<0.05$. This implied that the model gave better prediction more than a model with no predictor variables. This further indicated that the model provided a goodness-of-fit for the data. The model coefficients are as shown in Table 5.

Table 5

Coefficients for the Influence of Teacher Supervision on the Level of Teacher Stress

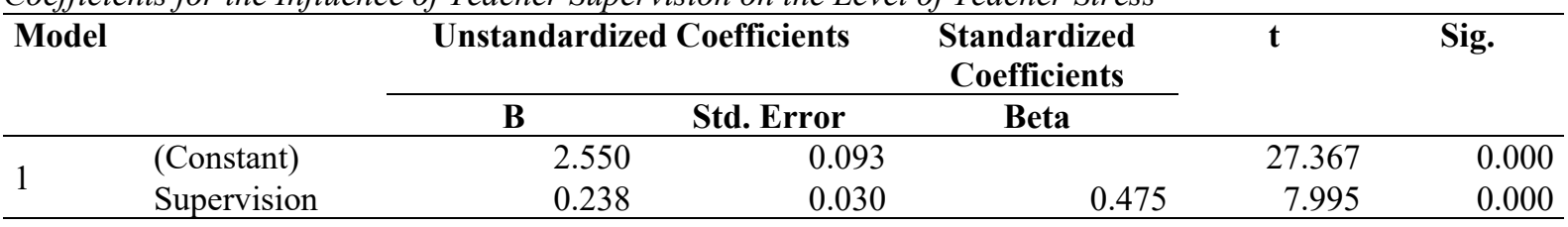

Dependent Variable: Stress

The study established that there was a significant relationship between the teachers' supervision and teacher stress. In respect to this, it was established that a one-unit increase in the teachers' stress led to 0.238 units increase in the level of teachers' stress when other factors were held constant. This is due to unstandardized beta coefficient of 0.238 . The t-statistic obtained was 7.995 which was significant at $5 \%$ significance level. In respect to this, supervision was found to be a significant predictor of teachers stress. Therefore the first hypothesis of the study was rejected and concluded that there is statistically significant influence of supervision on stress levels of primary school teachers in Kajiado Central Sub-County, Kenya. From these results, the following equation was formulated; Teachers' Stress $=2.550+0.238$ (Teacher Supervision $)+0.12891$

The findings of this study agreed with Pokhrel (2017) who established that if the head teacher is cooperative, democratic and friendly, the teachers was motivated and become more responsible in their job. The study also concurred with a study by Njoroge, (2015) established that teachers who perceived their principal's supervision as participatory were significantly more satisfied with their job than those perceived the principal's supervision as domineering. Borg, Kembro, Notander, Petersson, and Ohlsson (2017) notes that the success of any organization depends entirely on how effectively its workers are supervised. Teachers are directly under the head teachers' supervision, who plays a vital role on the motivation of the teachers. Yang (2014) established that there was a positive and significant influence of supervision on stress levels of workers.

\section{Recommendation and Conclusions}

It was concluded that there is statistically significant influence of supervision on stress levels of primary school teachers in Kajiado Central Sub-County, Kenya.

\subsection{Recommendations of the Study}

The study recommends that the Ministry of Education should take teachers' Supervision as a priority to enhance the psychological wellbeing of teachers in the provision of a safe place for emotional ventilation with a view of reducing the teachers' stress levels

The study recommends that the education stakeholders should consider putting a Guidance and Counseling 
program to support the Teachers manage their stress levels. This will motivate them for optimal productivity and job satisfaction.

For future research, an investigation would be done among students in the secondary schools and higher institutions of learning to establish the influence of motivational factors on stress levels. Further studies should be carried to establish gender differences in the stress levels of teachers in primary schools. An examination of adherence to the ministry of education policies addressing supervision of teachers in both primary and secondary levels of education may also be investigated.

\section{REFERENCES}

Afful-Broni, A. (2012). Relationship between Motivation and Job Performance at the University of Mines and Technology, Tarkwa, Ghana: Leadership Lessons, Creative Education, 3(3): 309-314.

Aguti, S. (2015). School Inspection and its Influence in the Quality Development of Inclusive Education Practices in Uganda. University of Oslo.

Aikman, S. \& Unterhalter, E. (2005). Beyond Access: Transforming policy and practice for gender equality in education. London: Oxford

Alam, T. (2011). Factors Affecting Teachers Motivation. International Journal of Business and Social Science, 2(1),298-304

Alderman, M. K. (2008). Motivation for Achievement: Possibilities for Teaching and Learning. New York, NY: Routledge.

Anbu, A. (2015). Professional Stress of Higher Secondary School Teachers. International Journal of Multidisciplinary Research and Development 2(1):1-3.

Aquinas, P.G. (2006). Human Resources Management: Principles and practices. New Delhi Publishing house.

Areekkuzhiyil, K. (2014). Factors Influencing the Original Stress among Teachers Working in Higher Education Sector in Keraha; An Empirical analysis. Journal Research and Pedagogic Interventions 2(2):1-15.

Aswathappa, L. (2005). Motivation and Experience: Work Experience and Satisfaction of Teachers' Needs. United Kingdom.

Bakker, A. B., \& Demerouti, E. (2007). The job demands-resources model: State of the Art. Journal of Managerial Psychology, 22, 309-328.

Balakrishnan, P., Bahari, S., \& Paul, J. (2017). Impact of Predisposing Factors on Academic Stress among PreService Teachers. International Journal of Medical Research \& Health Sciences, 6(10), 173-178.

Blix, G., Cruise, R. \& Mitchell, M. (2014). Occupational Stress among University Teachers. Educational Research, $36(2), 157-169$.

Briner, B. (2012). Occupational Stress Organization: Government School Teachers: Cause \& Preventive Measures. Available: http://www.worksafe.gov.au/biblio/ 0/111939'html

Dike, E., (2009). Nigerian Teachers Deserve Better Treatment. Abia, Nigeria

Galton, M., \& Macbeth, J. (2008). Teachers under Pressure. Sage. England

Gardner, S. (2010). Stress among Prospective Teachers: A Review of the Literature. Australian Journal Teacher Educ doi: 10.14221/ajte.2010v35n8.2

Hanif, M., Hafeez, S., \& Adnan, A. (2010). Factors Affecting Customer Satisfaction. International Research Journal of Finance and Economics, 60, 44-52.

Hoy, W.K., \& Miskel, C.G. (2008). Educational Administration: Theory, Research and Practice. United Kingdom

Jali, S, (2000). Some Factors Influencing Job Satisfaction \& Job Performance of Reading Teachers in the Division of Iligan City, A Proposal Training Program. Ph.D. dissertation, Dept. Educ., Liceode University.

Jarvis, T. (2002). Effect of the Challenger Experience on Elementary Children's Attitudes to Science. Journal of Research in Science Teaching. Volume 39, Issue 10. Pages 979-1000.

Johnston, S. (2018). Administrative Supports that Reduce Teacher Stress. Journal of Education and Social Policy, $1(1), 1-15$.

Karanja, T. (2009). The Impact of Free Primary Education on Participation of Girls in Public Primary Schools. A Case Study of Naivasha District (Doctoral dissertation).

Karihe, Namusonge \& Iravo (2015). Work Facilities as a Determinant of Occupational Stress and Employee Performance. International Journal of Science and Research4 (5)1925-1930.

Kenya Education Report. (2008). Teachers Motivation: Teacher Stress Forces Teachers to Look for Greener Pastures. Nairobi, Government Publishers.

Kenya National Union of Teachers. (2008). Kenya Education Report; Teacher Employment and Sustainability. Nairobi.

Kiruja, K., \& Mukuru, E. (2013). Effect of Motivation on Employee Performance in Public Middle Level Technical Training Institutions in Kenya. International Journal of Advances in Management and Economics, 2 (4): $73-82$

Kombo, K., \& Tromp, D. (2006). Proposal and Thesis Writing: An Introduction. Nairobi, Kenya: Paulines 
Publications Africa.

Kothari, R., (2004). Quantitative Techniques (3 ${ }^{\text {rd }}$ Ed). New Delhi: Vikas Publishing House.

Krejcie, V., Morgan, W. (1970). Determining Sample Size for Research Activities, Educational and Psychological Measurement, 30: 232-256.

Kyriacou, C. \& Chien, P. (2004). Teacher stress in Taiwanese primary schools. Journal of Educational Enquiry, 5(2), 86-104.

Lazarus, R.S. (1966). Psychological Stress and the Coping Process. New York: McGraw-Hill.

Lazarus, R.S., \& Folkman, S. (1984). Stress, Appraisal, and Coping. New York: Springer.

Meng, L. \& Liu, S. (2008). Mathematics Teacher Stress in Chinese Secondary Schools. Journal of Educational Enquiry, 8(1), 73-96.

MOEST. (2010). Sessional Paper No.1 of 2010: A Policy Framework for Education Training and Research. Government printer, Nairobi

Mugenda, M., \& Mugenda, G. (1999). Research Methods: Qualitative and Quantitative Approaches. Nairobi: Acts Press.

Mugenda, M., \& Mugenda, G. (2003). Research Methods Quantitative and Qualitative Approach. Nairobi: Acts Press.

Muriithi, D. (2011). The Role of Head Teacher as Instructional Supervisors in Kabarnet and Salawa Division in Baringo District, Kenya. Moi University press.

Mwenda, B. (2013). Influence of Teachers Institutional Motivational on Pupil's Performance at Kenya Certificate of Primary Education in Public Schools, Ndoleli Division, Kenya. University of Nairobi

Nadeem, M., Rana, M. S., Lone, A. H., Maqbool, S., Naz, K. \& Ali, A. (2011). Teacher's Competencies and Factors Affecting the Performance of Female Teachers in Bahawalpur (Southern Punjab) Pakistan. International Journal of Business and Social Science, 2(19), 217-222.

Ngari, K. (2013). Stress Levels Among School Administrators and its Implications On Management. Unpublished research thesis. University of Nairobi.

Njogu, N. N. (2011). Influence of Motivation On Teachers On Job Performance in Public secondary in Kirinyaga central. University of Nairobi.

Okeke, O. \& Dlamin, C. (2013). An Empirical Study of Stressors that Impinge on Teachers in Secondary Schools in Swaziland South African. Journal of Education; 33(1): 1-12.

Okumbe, J.A. (1992). "Levels of Job Satisfaction Among Graduate Teachers in Secondary Schools in Siaya District and Kisumu Town". PhD Thesis, University of Nairobi.

Ololube, P. O. (2006). Teachers Job Satisfaction and Motivation for school effectiveness: An assessment. Masters of Business Administration Thesis. University of Halsmti Finland.

Ousmame. (2013). An Empirical Survey of Frontier Efficiency Measurement Techniques in Education. Education Economics, 9(3): 245-268

Pokhrel, A. (2017). A Study of Occupational Stress among Secondary School Teachers' of Sikkim. Unpublished degree of Master in Philosophy Thesis: Sikkim University. Retrieved from http://14.139.206.50:8080/jspui/bitstream/1/4731/1/Anupam Pokhrel-MPhil-Education.pdf

Ramlall, S. (2004). A Review of Employee Motivation Theories and their Applications for Employee Retention within Organisations. American Academy of Business, 5, 52 - 63.

Sariah, S., Hassan, S., \& Ibrahim, A. A. (2018). The Art of Teaching Science in Secondary Schools : A Meta Analysis. TOJET: The Turkish Online Journal of Educational Technology, 17(1), 183-191.

Saqib, M., \& Rehman, K. U. (2018). Impact of Stress on Students Academic Performance at Secondary School Level at District Vehari. International Journal of Learning and Development, 8(1), 84. https://doi.org/10.5296/ijld.v8i1.12063

Sheldon, C. (1994). The Relationship between Leadership Style and Employee Performance: A Case Study of Real Estate Registration Organization of Tehran Province. Singapore Journal of Business Economics and Management Studies, Vol. 2 (5), pp. 21-29.

Sobe, M., (2013). Influence of Head Teachers' Motivational Practices on Teacher Performance in Public Primary Schools in Ikerege Division, Kuria West District, Kenya. Unpublished Thesis.

Sprenger, K. (2011). Rethinking Teacher Evaluation in the Third World: The Case of Kenya. Journal of Educational Administration, Vol. 30, No. 2, p. 213-229.

Sulaiman, F.R. \& Akinsanya, P.O. (2014). Stress and Instructors' Efficiency in Ogun State Universities: Implications for Nigerian Educational Policy. International Journal of Psychology and Counselling, Vol. 3(1), pp 9-14

TSC Kajiado County Office. (2017). Education Records. Kenya, Government printers.

Tyner, C. (2007). Theory of Employee Motivation: Herzberg's Two-Factor Theory. Retrieved http://voices.yahoo.com/theory-employee-motivation-herzbergs-two-factor

UNESCO, (2015). Rethinking Education, Towards a Global Common Good, UNESCO, France 
Wangai, M. M. (2012). Factors Affecting Job Satisfaction among Secondary School Teachers of Mwatate District, Kenya. Unpublished research thesis, University of Nairobi.

Wanzare, Z. O. (2002). Rethinking Teacher Evaluation in the Third World: The Case of Kenya. Journal of Educational Administration, Vol. 30, No. 2, p. 213-229.

Wigfield, A., Guthrie, J. T., Tonks, S., \& Perencevich, C. (2004). Children's Motivation for Reading: Domain Specificity and Instructional Influences. Journal of Educational Research, 97, 299-309.

Yang, K. (2014). Factors Affecting Internal Efficiency of Primary Schools in Nuer Zone of Gambella Regional State Institute of Education and Professional Development Studiesdepartment of Educational Planning and Management. Unpublished Doctor of Arts Thesis: Jimma University.

Yong, G. D. (2018). A Study of Job Stress on Job Satisfaction among University Staff in Malaysia : Empirical Study. European Journal of Social Sciences, 8(1), 121-131. 